\title{
Why Countries Are Fiscally Decentralizing
}

\author{
Mohammad Arzaghi \\ Vernon Henderson
}
Department of Economics, Brown University 64 Waterman St. Providence, RI 02912

December, 2002

We thank Enrico Spolaore for early advice and Rajiv Vohra for helpful discussions on the topic. We are also grateful to James C. Davis for his help throughout the project, Christine Kearney for preparation of the federalism index, and Fumiko Tamura for her help as a research assistant. Finally we thank two anonymous referees and an editor for helpful detailed comments. 


\section{Introduction}

Over the last twenty-five years, there has been an international movement towards both institutional and fiscal decentralization. Fiscally, the role of regional governments has expanded, in the sense that the share of state/provincial and local governments in total government consumption has risen. Sometimes the rise is preceded, accompanied, or followed by a change in formal institutional structures, where countries may adopt a federal constitution or embark on local democratization with elected local or regional governments. In the paper we model the economic forces that would promote formal institutional change towards a greater degree of federalism, and test the empirical implications of the model. As such, in some of the empirical work and in the early discussion of world trends we will look at development of formal institutions. However a country which in the data has a formal federal structure may still be de facto highly centralized, in that the local or regional governments have little fiscal responsibilities; and a country with a formal unitary structure may be de facto highly decentralized fiscally. Constitutional changes are discrete events which in certain contexts may be difficult culturally and politically to achieve. Thus we will also examine the actual extent of fiscal decentralization, which may be more revealing about underlying forces for decentralization in certain contexts.

In the model, we will argue that income and population growth and shifts in relative population across regions of countries, which occur during economic development, explain the move toward greater federalism and greater fiscal decentralization, both in theory and in our empirical results. We start by examining some of these patterns of change, as well as related changes in the extent of democratization and we review the literature on federalism and fiscal decentralization.

\subsection{Patterns of Institutional and Fiscal Decentralization}

For a sample of 48 countries with populations over 10 million in 1990, we construct a federalism index every five years from 1960-1995. The index varies from zero to four, with higher values meaning a greater degree of institutional regional autonomy. The description of the index is in the data Appendix, but it is based 
on official governmental structure (unitary versus federal) and the degree of autonomy and democratization of state/provincial and municipal governments. Later in the paper we will break the index into some of its component parts in the empirical work. Figure 1 shows how the index varies worldwide and by regions of the world. After 1975 or 1980, both worldwide and in all regions the index rises. It rises from a world average of 1.03 in 1975 to 1.94 by 1995 . There are significant differences among the regions. Developed countries tend to be more federalized to begin with. Latin American countries reached the same level of federalism as developed countries in 1995, with former Soviet bloc countries not far behind. Only countries in the Middle East and North Africa have little local autonomy, with minor changes over time.

Federalism and democratization seem to go hand-in-hand, as expected. First democratization involves representative government and a voice for regional interests. Arguably that leads to a greater call for regional autonomy. In addition one third of our federalism index reflects local and regional democratization, which may be correlated with national democratization. Indeed the simple correlation between our federalism index and a national democracy index is 0.63 for five years intervals over the period of $1960-1995$, and the correlation between changes in those indices is 0.39 over the same time period. The democratization index is based on Jaggers and Gar (1995), who used Polity III indicators on autocracy and democracy, and it ranges from -10 (least democratic and most autocratic) to +10 . Figure 2 shows democratization trends for the world. The pattern is similar to that for federalism.

Indices of changes in formal government structures have the limitation that the "de facto" situation may differ from the formal situation, with formal structures changing infrequently. For example between 1975 and 1985, federalism only changes in 9 of 48 countries; and between 1985 and 1995 it changes in 22 countries. One can argue that changes in formal structures towards enhanced local autonomy and democratization are the key elements, since they represent a structural change with some degree of permanence and guarantees. However more subtle changes in de facto situations are more likely to be reflected in a continuous measure, such as the share of state and local governments in government expenditures. Using IMF data, we constructed a variety of measures representing the degree of centralization. However, we tend to rely on one, which is the 
share of the central government in total government current consumption. This measure, as will be discussed below, excludes transfer payments.

The time coverage for these data is 1975,1985 , and 1995, involving respectively 39,47 and 48 countries. The average central government share is graphed in Figure 3. Consistent with the changes in formal structures, the world average for fiscal centralization declines from 0.74 in 1975 to 0.64 in 1995 . An average weighted by country population drops from 0.62 to 0.52 . Again there are significant regional differences. Developed countries and countries in the former Soviet bloc and Latin America have the lowest centralization while Middle Eastern and Sub-Saharan African countries have the highest centralization. The share of the central government drops in all regions, with an exception of former Soviet bloc countries in the period of 1985 to $1995 .^{1}$

The overlap in country coverage between our centralization measure and the federalism measure is limited, a total of 65 country-years over 1975, 1985, and 1995. Overall the correlation in levels for those years is high as would be expected: -0.75 ; and the correlation in changes is -0.60 for $1975-1985$ and -0.11 for $1985-1995$. We tried to examine whether correlations in leads and lags are important - for example, do changes in federalism precede changes in shares (i.e., institutions change before outcomes) or vice versa (i.e., institutional changes simply formalize changes in outcomes that have already occurred). Given the limited samples, there is absolutely no clear pattern for that ${ }^{2}$ and, in general, contemporaneous correlations are more consistent over time.

\subsection{Literature}

There is an enormous normative literature on the role of regional governments (Tiebout (1956), Oates (1972), Musgrave (1959, 1969), Starrett (1980), Hochman, Pines, and Thisse (1995), Persson, Roland, and Tabellini (1996), Persson and Tabellini (1999)), which examines issues such as, (a) the efficiency gains from

\footnotetext{
${ }^{1}$ However only Bulgaria, Hungary, Poland, and Romania from former Soviet bloc countries are represented in 1985 and 1995.

${ }^{2}$ For example the correlation between changes in shares and lagged changes in federalism are -0.39 for $85-95$ and 0.24 for 75-85. The correlation between changes in federalism (85-95) and lagged shares (75-85) is -0.22. But all of these correlations are affected by many zero values for changes the in federalism index.
} 
fiscal decentralization, (b) the responsibilities of the central versus regional governments, (c) the optimal number of tiers of government, and (d) better institutional arrangements between the center and regional governments. However, the positive issue of why and when decentralization occurs has received much less attention. Yet it seems that there ought to be a relationship between economic growth and the evolution of political institutions.

Decentralization is a complex process and is a product of many factors including cultural heritage and geography. De Tocqueville wrote "As impossible to determine beforehand, with any degree of accuracy, the share of authority which each of two governments to enjoy, as to foresee all incident $[\mathrm{s}]$ in the existence of a nation. ${ }^{\prime 3}$ However, the positive literature on decentralization does suggest that there appear to be certain empirical regularities concerning forces that promote decentralization (Oates (1972), Oates and Wallis (1988)). And there is now a start on theoretical modeling of the decentralization process (Panizza (1999)). We review these key works.

In his 1972 book, Oates, before turning to empirical evidence, argues that there are fundamental considerations that exert predictable and important effects on institutional and fiscal structures. In particular:

1. As per capita income rises, public expenditures rise disproportionately, so government plays a more dominant role in more developed countries. This has important consequences for decentralization. Oates and Wallis (1988) argue that relative public sector expansion allows better exploitation of scale economies in local public good provision, making local provision more feasible. However, as an offset, centralized income redistribution policies take on greater relative importance with development. Given this, as noted earlier, we separate out government consumption from redistribution, in order to focus on fiscal decentralization of government provision of actual goods and services.

2. Country size plays an important role. In larger countries again scale economies may be more properly exploited in local public provision. Additionally, more distant hinterland regions may be poorly served

\footnotetext{
${ }^{3}$ Democracy in America, Chapter VIII.
} 
by the center, due to higher transportation costs, poor information, and inattention of the center to demands of hinterland regions with different ethnic backgrounds and preferences. These bring pressures to decentralize (Tiebout (1956)).

Empirically Oates (1972) focuses on the "de facto" situation, examining fiscal rather than institutional decentralization. He examines four measures of fiscal centralization: share of total public revenue collected by the central government, share of the central government in all public expenditures (including transfer payments), share of the central government in current government consumption expenditures, and share of the central government in civil consumption expenditures (excludes defense). We tend to rely on the third - the share of the central government in consumption expenditures. Looking just at revenue collection, even in federalized countries, the center may collect substantial portions of revenue for regions because of scale economies in the revenue collection process, remitting certain proceeds to the regions. In terms of transfer payments, regardless of how federalized a country is, central governments generally undertake income redistribution. Thus, fiscal decentralization is measured better by government consumption. While excluding national defense, the other uniformly centrally provided good, is desirable in measuring fiscal decentralization, data limitations on recorded defense expenditures rule this out. In his cross-country analysis, Oates (1972) finds that for all four centralization measures, larger and richer countries are more decentralized. ${ }^{4}$

In an important recent study, Panizza (1999) constructs a formal model of fiscal decentralization. He has a spatially linear country with a uniform distribution of population. The level of all public goods and services are determined at the national level and based on majority rule (median voter). The national government provides part of the goods and services to the people, which only reach them after spatial decay. The rest are provided by nearby local governments and are subject to much smaller spatial decay. The national government which wants to maximize its own size decides its share in provision of public goods

\footnotetext{
${ }^{4}$ Oates and Wallis (1988) look at decentralization within states for 48 USA states in a panel context, allowing for better control of inter-regional geographic and cultural differences. They find that the share of the state government in total local government expenditures including transfers rises with income, reflecting the enhanced role of state governments relative to city and government in income redistribution in recent decades.
} 
and services, accounting for how that share influences voters' demands for the overall level of public goods. Since voters benefit more from local provision, which avoids higher spatial decay, too high a national share reduces overall voter demand for public services. Thus the degree of decentralization is a choice made by the national government, and local governments are passive. Using similar indices as Oates (1972), Panizza finds that fiscal centralization is negatively correlated with country size, income per capita, level of democracy, and ethnic fractionalization, using cross-sectional methods of data analysis.

We will borrow aspects of Panizza's model, but will focus on regional demands for institutional decentralization drawing on the literature on secession (Buchanan and Faith (1987), Bolton and Roland (1997), Alesina and Spolaore (1997)). In essence we will view institutional decentralization or greater federalism, as a response to rising demands of hinterlands for greater autonomy ${ }^{5}$. In the model, with formal institutional decentralization comes fiscal decentralization, so the two go hand-in-hand.

Section 2 contains a theoretical model, which captures the different aspects of decentralization. In section 3, we will summarize testable hypotheses that are direct implications of the model in section 2 and we will choose an empirical specification to test them. Section 4 includes the results of different econometric approaches to the empirical specification. Section 5 concludes. In the appendix, we provide a detailed description of the variables.

\section{The Model}

In this section, we present a simple model of "separation", or "internal exit". By separation we mean the establishment of new local political units within a country that has been previously governed under a strong unitary system. These new units are local and autonomous and they provide local public goods to their constituents, rather than relying on a unitary government to provide these goods. In other words, separation is the move from a strong unitary system to a strong federal system. As an example of strong unitary

\footnotetext{
${ }^{5}$ Besley and Coate (1999) compare the operations of representative centralized democracy in providing local goods at a national level with that of decentralized provision where local legislatures choose their own goods. This is more in the normative tradition of what works the best.
} 
system we think of many Middle Eastern countries such as Egypt or Yemen, while an example of a strong federal system is Canada. A full formal move to a strong federal system where federalism in Figure 1 takes a value of four is unusual, only occurring twice (Brazil and Argentina) in the period 1960 to 1995 in our data. However, by modelling that process, we identify the forces that underlie a desire for separation. Such forces, even without formal separation, may affect the stance of central and local governments beyond the current political structure and may cause a shift in the relative power among them. In other words, a more credible threat of separation might cause an increased willingness of the central government to share power and responsibility with regional governments.

In our model we consider a country that comprises two regions. We name region 1 , the coastal region, and region 2, the hinterland region. The country has a unitary government, which is located in the coastal region. The unitary government provides local public goods to both regions. In the spirit of Buchanan and Faith (1978), we ask under what conditions the hinterland region would want to separate ${ }^{6}$. By separation, we mean that the hinterland region is willing to set up and finance a regional government in order to provide its own local public goods. That does not preclude the national government from providing a set of national public goods to both regions, although, we formally ignore this possibility for the sake of simplicity.

In modeling separation, we consider three scenarios. In the base scenario, the population and individual incomes are fixed in each region and governmental institutions are perfectly democratic. As the first extension, we deviate from the base scenario by considering limited or partial democracy. The officials in the central or local governments are elected by majority rule but they carry some leverage over the magnitude of publicly provided goods. Further, as the second extension, we consider a case with a mobile population. In this case both population and income in the two regions are endogenous.

\footnotetext{
${ }^{6}$ Our model crucially deviates from the one in Buchanan and Faith (1987). They look at internal exit threat as a powerful tool to limit ability of the central government to exploit peripheral communities (minorities) for the sake of the majority of the population. However, we will view the threat of internal exit as a limit on the ability of a partially democratic unitary government to ignore voters' tastes in general and, in particular, in the hinterland region. That is to say, the unitary government is willing to devolve more power and responsibility when the threat of internal exit is more credible. Another difference is that they model the conflict between classes and we will model the conflict between geographical regions.
} 


\subsection{The Base Scenario: Immobile Population and Exogenous Income under Perfect Democracy}

We start by introducing the building blocks of the model and characteristics of the players. Then, we explain the structure of the game and derive outcomes. Finally, we draw some testable implications of the outcomes in a set of comparative statics results.

\section{Regions}

There are two regions. The population of region 1 is $L_{1}$ and region 2 is $L_{2}$, and therefore the national population is $L=L_{1}+L_{2}$. We assume $L_{1}>L_{2}$, which means that the coastal region is the dominant region in the union ${ }^{7}$. Individuals receive the same income within each region, but incomes generally differ across regions. We indicate individual incomes in region 1 and region 2 with $y_{1}$ and $y_{2}$, respectively. Preferences of all individuals have the same functional form

$$
u=C x^{\alpha} g^{\beta}, \quad \alpha+\beta=1
$$

where $x$ is a private good produced and sold at price 1 (normalized) and $g$ is a local public good. Without loss of generality we assume $\alpha+\beta=1$. We could allow preferences to differ across regions, and that is an obvious force for "separation". However, we choose to simply focus just on pure economic factors promoting separation $^{8}$, rather than relying on differences in preferences.

In the public sector, local public goods are financed by a proportional tax on income. Therefore, utility of an individual in region $i$ is

$$
u_{i}=C y_{i}^{\alpha}\left(1-t_{i}\right)^{\alpha} g_{i}^{\beta}
$$

where $t_{i}$ and $g_{i}$ are the tax rate and level of public services, respectively, faced by people in region $i$.

\footnotetext{
${ }^{7}$ This assumption does not play any role in the first scenario and the analysis and the results are the same for $L_{1} \leq L_{2}$. However, this assumption is crucial to the specific results in the second scenario.

${ }^{8}$ Having the same preferences also facilitates the last scenario where the population is mobile across regions and there is no clear way to classify preferences by regions. We will revisit this issue in footnote 9 .
} 


\section{Unitary Government}

There is a fixed cost $F$ of maintaining a government. The government in the coastal region only accounts for the preferences of the people in the coastal region, who are the majority in the voting process. The national constitution requires that:

1. All the individuals face the same tax rate $t$

2. Public expenditure per capita $g$ is the same in the two regions

Thus, the central government budget constraint for provision of public goods is

$$
Y t=F+\left(L_{1}+L_{2}\right) g, \quad Y \equiv L_{1} y_{1}+L_{2} y_{2}
$$

assuming the cost per unit of public goods is $1 . Y$ is national income and the national tax base. Using the fact that $L_{1}+L_{2}=L$, we rewrite the budget constraint as

$$
t=(F+g L) / Y
$$

Note we model local public goods as Samuelson private goods (or fully congestible goods). Consequently, the only source of scale effects in governance arises from the presence of $F$. Under the national constitution, fiscal discrimination of the center against a peripheral region is ruled out, since again that is an obvious force promoting separation.

Under a unitary government, a dollar spent on public goods in the coastal region provides a unit of local public goods. But a dollar spent by the central government on local public goods in the hinterland region only results in $(1-\delta)$ effective units of public goods. So following Panizza (1999), there is "spatial decay", which could represent political or economic costs of providing $g$ in a more distant region. These costs could include issues of monitoring corruption or inefficiency in the provision and delivery of local public goods as well as transportation costs. In a sense "spatial decay" could also represent differences of taste or production 
technology. These exist because a unitary government tailors the features of the local public goods to the needs of the people in the coastal region (national median voter), but those features might not appeal to hinterland voters or suit their needs given geographical differences between the regions and appropriate type of service delivery for that geography. For example, the organization of school systems in congested urban areas may not fit the needs of sparsely populated rural areas. ${ }^{9}$

Therefore, under a unitary government by using (1) and (2), the utility of people in region 1 is

$$
u_{1}=C y_{1}^{\alpha}\left(1-\frac{F}{Y}-\frac{g L}{Y}\right)^{\alpha} g^{\beta}
$$

while the utility of an individual in region 2 has similar form except that the effective level of local public goods that they receive is only $g_{2}=(1-\delta) g$.

$$
u_{2}=C y_{2}^{\alpha}\left(1-\frac{F}{Y}-\frac{g L}{Y}\right)^{\alpha} g^{\beta}(1-\delta)^{\beta}
$$

Under a unitary government and a perfect democracy scenario, we know that $g$ is chosen to maximize the preferences of the median voter in the coastal region. However, given the form to preferences and under perfect democracy, it turns out voters in both regions want the same level of public goods. The choice of $g$ which maximizes $(3 \mathrm{a})$ and $(3 \mathrm{~b})$ is

$$
g^{*}=\beta\left(\frac{Y-F}{L}\right)
$$

\footnotetext{
${ }^{9}$ Note that we model spatial decay as a depreciation factor applied to local public goods provided to region 2 under a unitary system. So, there is no real heterogeneity in tastes between two regions. They both value the public good the same way, but because of decay individuals in the hinterland receive an effective lower level of public goods. Therefore, there is no possible way to effectively deter the secession, since the optimal level of public goods (under a unitary government) is the same in two regions. An alternative way is to introduce real taste differences between the regions, for example

$$
u_{2}=C x_{2}^{\alpha} g^{\beta \delta}
$$

which $\delta$ represents the level of heterogeneity $(0 \leq \delta \leq 1)$. Then an optimal level of local public goods is different among the two region even when the two regions face the same budget constraint. In other words, the optimal level of local public goods would be different in new (3a) and (3b).
} 
and utilities under a unitary government in region 1 and region 2 respectively are

$$
\begin{aligned}
& u_{1}^{*}=C_{0} y_{1}\left(1-\frac{F}{Y}\right)\left(\frac{Y}{y_{1} L}\right)^{\beta} \\
& u_{2}^{*}=C_{0} y_{2}\left(1-\frac{F}{Y}\right)\left(\frac{Y}{y_{2} L}\right)^{\beta}(1-\delta)^{\beta}
\end{aligned}
$$

where

$$
C_{0}=C \alpha^{\alpha} \beta^{\beta}
$$

\section{$\underline{\text { Federal Structure }}$}

Under a federal structure, each region operates independently. Now, each region $i$ must separately bear a fixed cost of running a government $F_{i}$. In general, we will consider $F_{1}=F_{2}=F$. One might argue that regional governments are cheaper to operate than national ones so $F_{2}<F$. However one could consider also an additional cost to separation itself apart from the fixed cost of having a government, so that $F_{2}>F$. Under separation, regional budget constraints are $t_{i} L_{i} y_{i}=F_{i}+g_{i} L_{i}$, so the required tax rate to provide $g_{i}$ level of local public goods in region $i$ is

$$
t_{i}=\frac{F_{i}}{L_{i} y_{i}}+\frac{g_{i}}{y_{i}} \quad i=1,2
$$

By substituting the tax rate from (6) into (1), we rewrite the utility of individuals in region $i$ as

$$
u_{i}=C\left(y_{i}-\frac{F_{i}}{L_{i}}-g_{i}\right)^{\alpha} g_{i}^{\beta} \quad i=1,2
$$

Note that since each region provides its own local public goods now, there is no spatial decay of $g_{2}$. It is a clear benefit of separation to individuals in region 2 . 
The optimum choice of $g_{i}$ and maximum utility are as follow

$$
\begin{gathered}
g_{i}^{* *}=\beta\left(y_{i}-\frac{F_{i}}{L_{i}}\right) \\
u_{i}^{* *}=C_{0}\left(y_{i}-\frac{F_{i}}{L_{i}}\right) \quad i=1,2
\end{gathered}
$$

where $C_{0}$ is defined in $(5 \mathrm{c})$.

\section{The Separation Process}

We evaluate the costs and the benefits of separation to the hinterland region to indicate the economic forces favoring separation and federalism compared to a unitary structure. In so doing, we posit a separation game, where separation is decided by referendum among the voters in hinterland region. While a referendum is a simple and perhaps unrealistic separation device given the complex political structures of most countries, for practical purposes it suffices to identify the forces behind separation.

In general, because region 1 has the majority, it can impose its best choice of local public goods on the nation subject to two fundamental conditions of unitary government: uniform tax, i.e. $t_{1}=t_{2}=t$ and equal provision of local public goods, i.e. $g_{1}=g_{2}=g$. The fact that the regions might be better off by setting their own tax rates and local public good provision is a reason for separation.

Before starting our analysis, we must consider the possibility of separation by region 1 . In our analysis, we assume that region 1 is not in favor of separation. For example, if regions are of equal size and $F_{1} \leq F$, then if $y_{2}<<y_{1}$ even though region 1 controls the political process, and the fixed cost of government, $F$, is shared, a unitary structure implies they pay a disproportionate share of national taxes and they would be better off under separation, and never having a unitary structure to begin with. To avoid this possibility, we assume the following condition is satisfied within a unitary structure:

$$
1-\frac{F_{1}}{y_{1} L_{1}}<\left(1-\frac{F}{Y}\right)\left(\frac{Y}{y_{1} L}\right)^{\beta}
$$


This inequality compares utility under federation, i.e. equation (8), with that under a unitary structure, i.e. equation (5a) for region 1.

To evaluate whether region 2 separates or not, we posit a staged game . In the first stage, the government announces a level of $\widehat{g}$ that will be provided under a unitary structure. In the second stage, voters in region 2 vote whether to remain in the union (and "accept" $\widehat{g}$ ) or to separate (and have a federal structure). In the third stage, after the matter of separation has been resolved and the post-referendum political structure has been realized, the political process operates to determine the level of local public goods. If a unitary structure prevails, sequential rationality requires the political process in fact delivers the $\widehat{g}$ promised in stage 1. If a federal structure prevails, regions 1 and 2 form local governments and the local governments provide local public goods $g_{1}^{* *}$ and $g_{2}^{* *}$ as in (7).

The only equilibrium strategy to deter separation for a unitary government is to announce $\widehat{g}=g^{*}$ in the first stage. From (4) $g^{*}$ maximizes the utility of the majority in region 1, but it also maximizes the utility of region 2 people under a unitary structure, so a unitary government cannot make anybody better off by deviating from $g^{*}$. However, there are other circumstances where the unitary government may promise a $\widehat{g}$ different from $g^{*}$ in order to deter separation by region 2 , as we will see in the next scenario.

In this context, the decision regarding separation comes down to comparing the utility of people in region 2 in (5a) under a unitary government with their utility in (8) under a federal structure. A unitary structure will prevail if

$$
1-\frac{F_{2}}{y_{2} L_{2}} \leq\left(1-\frac{F}{Y}\right)\left(\frac{Y}{L y_{2}}\right)^{\beta}(1-\delta)^{\beta}
$$

or otherwise separation will occur. If (10), holds there will be a unitary government where $g^{*}$ of local public goods in (4) is provided to people in both regions. Otherwise, region 2 will separate and each regional government will provide local public goods of $g_{i}^{* *}$ in (7). In deciding whether to separate, people in region 2 are comparing the benefits (no spatial decay in public good provision and uniform local demand for public goods) with the costs (additional fixed costs per capita of running a separate local government), accounting 
for the amount of fiscal subsidies they receive under a unitary structure when $y_{1}>y_{2}$ and the fact that they contribute less than average taxes.

The evaluation has excluded transfer payments. That would be an important extension. For example, if the inequality in (10) is not satisfied, in theory there is room for region 1 residents who control the unitary government to bribe region 2 voters to remain in the union, through transfer payments. For credibility, either transfer formulas would need to be part of the constitution or the game structured so that a unitary structure is only maintained as long as promised transfers are actually carried out. While transfer payments would enhance the RHS of (10), generally the same forces promoting separation are at work. It is the forces we are interested in, not the quantitative point at which they dominate. For example, an increase in $\delta$ or decline in $F_{2}$ increases the benefits of separation, and at some point the transfer payments that region 1 would be willing to make wouldn't be enough to deter separation.

\section{Comparative Statics}

The following empirical hypotheses emerge from an analysis of inequality (10). Most of these are obvious; and they are related to Panizza's (1999) analysis of fiscal decentralization, even though we are looking at institutional decentralization. They provide a benchmark, for the next sections.

1. If the degree of "spatial decay" increases on the RHS of (10), the relative gain from separation rises. There should be a greater tendency toward internal exit in countries with higher geographic or ethnic diversity, larger area, or other potential forces for spatial decay.

2. Obviously, if $F_{2}$ rises, the relative gain from separation falls. If $F=F_{2}$ and they both rise together the relative gain from separation still falls. Specifically if we start from equality in (10), as $F$ and $F_{2}$ rise, differentiation shows that the decline of the LHS exceeds the decline of the RHS.

3. Holding $\frac{y_{1}}{y_{2}}$ fixed (the degree of income inequality), if $y_{1}$ and $y_{2}$ rise (due to economic growth) the relative gain from separation rises because the fixed cost of separation is more affordable in region 2. This follows, as in item 2 , by differentiation, noting that $y_{2} / Y$ is not changing $\left(d y_{2} / y_{2}=d Y / Y\right)$, and 
$F / F_{2} \leq 2$.

4. Holding $y_{2}$ constant, if $y_{1}$ (and hence $Y$ ) increases, the RHS of (10) increases, so that the gain from staying in a unitary structure increases for the hinterland region, since coastal residents now bear a larger portion of the cost of local public goods.

5. Holding $\frac{L_{2}}{L_{1}}$ constant, if $L$ (and hence $L_{2}$ ) increases then the cost of separation is divided among more people and therefore the per capita cost of separation declines. The analysis follows that in item $3{ }^{10}$

6. Finally, holding $L$ constant, if $L_{2}$ increases (and hence $L_{1}$ falls) and $y_{1} \geq y_{2}$, that increases the benefits of separation, since there are fewer coastal residents who bear more than their share of taxes in a unitary state. However if $y_{1}<y_{2}$ the effect is ambiguous: there are more $L_{2}$ people to split the costs of $F_{2}$ under separation, but there are fewer coastal residents who would be paying less than their share of taxes in a unitary state.

\subsection{Scenario 2: Partial Democracy with Immobile Population and Exogenous Income}

Replacing perfect democracy with partial democracy raises two new issues. First is to redefine the objective function of governments. Under perfectly democratic institutions, the objective function of the government was simply the utility of the median voter. But with partial democracy, under the Leviathan assumption of Buchanan and Faith (1987), politicians who enjoy having a bigger government, also may have some leverage to alter the choice of local public goods to partially achieve that goal. Thus, the new objective function of the government must capture the desires of both politicians and voters. Second, changing to partial democracy increases the complexity of the separation game. In the previous subsection, a specific deterrence strategy was not biting for the unitary government since it could not offer anything better to region 2 than what the

\footnotetext{
${ }^{10}$ Note in items 2 and 3 only the $\left(1-F_{2} /\left(y_{2} L_{2}\right)\right)$ and $(1-F / Y)$ terms are affected.
} 
political process would ordinarily provide under a unitary system in the third stage of the game. But now, the unitary government may have a biting strategy to deter separation. We now address these issues.

\section{$\underline{\text { Modeling Partial Democracy }}$}

How can we model partially democratic governments in a simple fashion that does not distract us from the examination of institutional decentralization in the context of one paper? Perfectly democratic institutions pass all the power to the median voter. However, under imperfect democracy in the political economy literature, politicians are able to exercise some power to accommodate their own desires. For example, in micro-foundation models with asymmetric information on both sides, in Persson, Roland, and Tabellini (1996) and Polo (1998) governments have some degree of power regardless of the democratic voting process ${ }^{11}$. In modeling partial democracy here, we want a simple representation of how politicians influence public good provision away from the choice of the median voter. Similar to Panizza (1999), we model partial democracy by assigning an objective function to the political process, which weighs the utility of median voters against the utility of politicians, where the weights represent the relative bargaining power of each party ${ }^{12}$.

We assume that the objective function of a government is

$$
W=\left[C y_{m}^{\alpha}\left(1-\frac{F}{Y}-\frac{g L}{Y}\right)^{\alpha} g^{\beta}\right]^{\theta}(g L)^{1-\theta}
$$

where the expression in the brackets is the utility of the median voter with income $y_{m}, g$ is the level of per capita local public goods, $Y$ the tax base as it is defined in (2), and $L$ is the population to be served. We have already substituted in for the tax rate, using the government budget constraint in (2). The second

\footnotetext{
${ }^{11}$ The ability of politicians to collect rents is a direct result of lack of perfect commitment (moral hazard) on the politicians side. Politicians can promise something but can deviate from their promises when they take the office. As Polo argues, the usual intuition that an increase in competition among politicians could drive their benefits from holding office to zero is not applicable here.

${ }^{12}$ The outcome of political process should be a Nash bargaining solution to an cooperative game between voters and politicians. The fact that both parties realize that lack of cooperation might result in very undesirable outcome, i.e. anarchy, persuades both to recognize the power of other party and leads them to an efficient outcome (Wittman (1990)). The outcome of such a cooperative game is formulated in axiomatic way by the Nash bargaining solution. The Nash solution carries all the desirable properties that we expect from the outcome of such game (Pareto efficiency, IUO, IUU, Symmetry, IR, IIA). The generalized Nash solution is characterized by maximization of an geometric weighted average of utility of voters and politicians. The weights come out of a bargaining game with alternating offers with impatience. Here, the voters' bargaining power might depend on their ability to protest and control excessively large government.
} 
term is the size of government, measured by total expenditures on local public goods. This represents the utility of politicians. The weight $\theta$ represents the degree of democracy. As $\theta \rightarrow 1$, we move toward the perfect democracy case (first scenario), where the only thing that matters is the utility of voters. As $\theta \rightarrow 0$, we approach social breakdown with a pure Leviathan outcome where politicians take all social resources (except perhaps what is needed for subsistence or to deter revolution, as in Alesina and Spoloare (2003)). Equation (11) can be interpreted as the Nash bargaining solution criterion function. The relevant part of the utility possibility frontier for this bargaining game is limited to the declining part of the function in the brackets $^{13}$. This part is concave and decreasing and therefore it satisfies all the properties of a well behaved utility frontier and will result in an unique Nash solution for the above objective function, where the threat points are for no government to form and no local public goods to be provided. An equilibrium level of local public goods is the point on the utility possibility frontier of the median voter and the politician that maximizes (11).

\section{Optimal Choices Under Different Institutional Structures}

We start by specifying the choice process and outcomes under a unitary and then a federal structure, before analyzing the separation process.

Unitary Structure. Under a unitary structure, where the coastal region has the majority, the objective function of the unitary government is

$$
W=\left[C y_{1}^{\alpha}\left(1-\frac{F}{Y}-\frac{g L}{Y}\right)^{\alpha} g^{\beta}\right]^{\theta}(g L)^{1-\theta}
$$

The level of $g$ that maximizes government's objective function in (12) is

$$
\tilde{g}=1-\theta(1-\beta)\left(\frac{Y-F}{L}\right)
$$

\footnotetext{
${ }^{13}$ If we show the utility of the politician (which is monotone on $g$ ) on the x-axis and of median voter on the y-axis, the utility possibility frontier is a bell shape curve. It rises from zero at $g=0$ and peaks at $g=g_{m}^{*}$ below in (14) and then declines to zero at $\bar{g}=y-\frac{F}{L}$.
} 
where $\tilde{g}>g^{*}$ in eq. (4) under a pure democracy unitary system. The corresponding utilities for the individuals in region 1 and 2 under a unitary structure at $\tilde{g}$ are

$$
\begin{aligned}
& \tilde{u}_{1}=C_{1} y_{1}\left(1-\frac{F}{Y}\right)\left(\frac{Y}{y_{1} L}\right)^{\beta} \\
& \tilde{u}_{2}=C_{1} y_{2}\left(1-\frac{F}{Y}\right)\left(\frac{Y}{y_{2} L}\right)^{\beta}(1-\delta)^{\beta}
\end{aligned}
$$

where

$$
C_{1}=C(1-\theta(1-\beta))^{\beta}(\alpha \theta)^{\alpha}
$$

Utilities of residents have exactly the same form as (5a) and (5b), except for the constant term, where $C_{1}$ under partial democracy is smaller than the constant term $C_{0}$ under perfect democracy. The fact that the median voter cannot achieve his best choice and maximum utility under a unitary system is a direct consequence of having a partial democracy rather than perfect democracy.

Federal Structure. Under a federal structure (post-separation) each region has its own government and provides its own local public goods. The objective function of region $i$ 's government is

$$
W_{i}=\left[C\left(y_{i}-\frac{F_{i}}{L_{i}}-g_{i}\right)^{\alpha} g_{i}^{\beta}\right]^{\theta_{i}}\left(g_{i} L_{i}\right)^{1-\theta_{i}} \quad i=1,2
$$

where $\theta_{i}$ is the level of democracy in region $i$. The optimal level of local public goods for the region $i$ is

$$
\widetilde{\widetilde{g}}_{i}=1-\theta_{i}(1-\beta)\left(y_{i}-\frac{F_{i}}{L_{i}}\right)
$$


and the utility of individuals in region $i$ at $\widetilde{\widetilde{g}}_{i}$ is

$$
\begin{aligned}
\widetilde{u}_{i} & =C_{1 i}\left(y_{i}-\frac{F_{i}}{L_{i}}\right) & i=1,2 \\
C_{1 i} & =C\left(1-\theta_{i}(1-\beta)\right)^{\beta}\left(\alpha \theta_{i}\right)^{\alpha} &
\end{aligned}
$$

Again, note that these equations are exactly the same as (8) except for the smaller constant terms. In general, in terms of preference structure, we assume a region 1 government involves the same politicians as a unitary government, while a region 2 government is a new set of politicians. Thus a region 1 regional government is simply a downsizing of the scope of the old unitary government.

\section{$\underline{\text { The Separation Process }}$}

We consider a game similar to the one in the previous scenario. The main difference is that now there may exist a viable strategy for the central government to offer a $g$ different from $\tilde{g}$ in order to deter separation. As before, the central government announces a level of local public goods $\widehat{g}$ in the first stage, then the region 2 decides whether to separate or not, and at the end, the political process delivers local public goods. Sequential rationality requires that any $\widehat{g}$ promised in the first stage of the game will be delivered by the political process in the third stage. Again, we assume that region 1 does not desire separation in the first place. In other words, the utility of individuals in region 1 under a unitary system is higher than under a federal system, or the following inequality holds

$$
C_{11}\left(y_{1}-\frac{F_{1}}{L_{1}}\right)<y_{1}^{\alpha}\left(1-\frac{F}{Y}-\frac{\widehat{g} L}{Y}\right)^{\alpha} \widehat{g}^{\beta}
$$

Separation only happens if individuals in region 2 vote for separation. Voters in region 2 compare their utility under a federal structure and under a unitary government. So, an unitary structure prevails if the 
following inequality holds

$$
C_{12}\left(y_{2}-\frac{F_{2}}{L_{2}}\right) \leq C_{1} y_{2}^{\alpha}\left(1-\frac{F}{Y}-\frac{\widehat{g} L}{Y}\right)^{\alpha} \widehat{g}^{\beta}(1-\delta)^{\beta}
$$

Case 1. Let's start with the case where the central government announces $\widehat{g}=\tilde{g}$ the level of local public goods in (13). If it satisfies (19); it satisfies sequential rationality, since it is maximizes the political process objective function in a unitary system. In that case (19) reduces to

$$
1-\frac{F_{2}}{y_{2} L_{2}} \leq\left(\frac{C_{1}}{C_{12}}\right)\left(1-\frac{F}{Y}\right)\left(\frac{Y}{L y_{2}}\right)^{\beta}(1-\delta)^{\beta}
$$

This simplifies further to the inequality in (10), if we assume that $\theta_{2}=\theta$, so $C_{1}=C_{12}$.

Therefore, the general level of democracy and changes in democracy are immaterial as long as $\theta=\theta_{2}$. The same set of comparative statics apply as in section 2.1. What happens when $\theta \neq \theta_{2}$ ? If $\theta_{2}$ is fixed and $\theta$ increases then the tendency toward separation decreases because $\frac{\partial C_{1}}{\partial \theta}>0$. By the same argument if $\theta_{2}$ increases (more democratic structure at local governments) then that increases the possibility of separation.

Case 2. Now suppose that $\tilde{g}$ does not deter separation by region 2. That is to say, the inequality (21) does not hold. However, in theory there could be room for the central government to maneuver, by moving $\widehat{g}$ away from $\tilde{g}$ and toward $g^{*}$ in (4), where $g^{*}<\tilde{g}$. Reducing public goods from $\tilde{g}$ towards $g^{*}$ increases the utility of voters (in both regions) up until $g^{*}$ is reached. The utility of politicians in the central government decreases as the level of local public goods falls. Therefore, the government only is interested in lowering public goods below $\tilde{g}$ just enough to deter separation. In other words, it sets $\widehat{g}=g_{d}\left(g_{d} \leq \tilde{g}\right)$ such that the (20) holds with equality

$$
C_{12} y_{2}\left(1-\frac{F_{2}}{y_{2} L_{2}}\right)=C_{1} y_{2}^{\alpha}\left(1-\frac{F}{Y}-\frac{g_{d} L}{Y}\right)^{\alpha}\left(g_{d}\right)^{\beta}(1-\delta)^{\beta}
$$

The deterrence strategy in theory works if equation (21) has a solution $g_{d}$ and its solution satisfies 
$g^{*} \leq g_{d} \leq \tilde{g}$. However, it may be that even at $\widehat{g}=g^{*}$ the inequality (19) does not hold and deterrence is not a viable strategy. In other words, if

$$
C_{12}\left(1-\frac{F_{2}}{y_{2} L_{2}}\right)>C_{0}\left(1-\frac{F}{Y}\right)\left(\frac{Y}{y_{2} L}\right)^{\beta}(1-\delta)^{\beta}
$$

separation is inevitable and the central government cannot deter it.

Note that in eq. (22) an increase in local democracy, which raises the LHS $\left(C_{12}\right)$ but leaves the RHS constant, will increase the possibility of separation. Later in the empirical section we will examine the effect of local democratization on decentralization.

There are a number of issues with this formulation of the separation process. First, is a promise of $\widehat{g}=g_{d}<\tilde{g}$ credible? In a sense it satisfies sequential rationality: voters are happy to have public goods reduced below $\widehat{g}$ (down to $g^{*}$ ) and the government is happy to deter separation. However, it is still the case that the political process in stage 2 is set to deliver $\widehat{g}$. So, when $\widehat{g}$ is set less than $\tilde{g}$, region 2 voters would need "guarantees" such as if the promised level of public goods are not delivered, they can revote and exit. Such a guarantee mechanism could also come out of a repeated (reputational) process. Second, setting $\widehat{g}<\tilde{g}$ violates the current Nash bargaining criterion per se. In essence by "mutual agreement" of the politicians and median voter, that rule is being suspended or amended. But that cries out for a reformulation of the bargaining game with new threat points or altered bargaining powers, but such reformulation isn't straightforward. ${ }^{14}$

Another issue is that, if the unitary government can amend $g$ to survive, then consider the "shadow" asyet-to-exist government in region 2. It could promise a lot just to exist, perhaps even credibly. For example, in the separation process, a shadow region 2 government could specify a more democratic constitution, competing with the unitary government over rules to ensure greater democracy. That is an interesting idea,

\footnotetext{
${ }^{14}$ For example, new threat points could involve what happens under separation to the median voter versus the unitary government. But those threat points in turn involve threat points about what happens under political breakdown in determining the level of public goods under separation. How to set this up is not obvious. Nor is it obvious how to model how $\theta$ increases, for example, as another way of trying to reformulate the bargaining process.
} 
where potential separation would induce greater political competition among levels of government to promote democracy at the national level.

Finally there is an issue of whether or not politicians in a unitary government want to deter separation, even assuming region 1 people prefer a unitary government to a federal system. Under a federal structure the

politicians in the coastal region receive utility of $L_{1} \widetilde{\widetilde{g}}_{1}$ for $\widetilde{\widetilde{g}}_{1}$ defined in (16). Alternatively, under a unitary structure when setting $\widehat{g}=g_{d}<\tilde{g}$ to deter entry, they receive utility of $L g_{d}$. While if $\widehat{g}=\widetilde{g}$, politicians always prefer a unitary structure, for $\widehat{g}=g_{d}<\tilde{g}$ it may not be the case. From (15), (16), and (21), it can be that $\widetilde{\widetilde{g}}_{1} \gg g^{*}$, and as $g_{d}$ approaches $g^{*}$ if $L_{1} \rightarrow L$, then $L_{1} \widetilde{\widetilde{g}}_{1}>L g_{d}$. That is, if region 2 has little population and low relative income, then the coastal region government under a federal structure may be larger than a unitary government. If the $g_{d}$ in (21) that deters separation leaves coastal politicians worse off, given they have an advantage of moving first in the game, they can announce $\widehat{g}$ equal to $\widetilde{g}$, and let separation occur, although the coastal voters would prefer a unitary system.

\subsection{Scenario 3: Mobile Population and Endogenous Income Under Perfect Democracy}

Now, we assume that the population is perfectly mobile across regions. This changes the whole analysis. While it complicates analysis of equilibria, it simplifies the condition under which separation occurs. With perfect mobility, an equilibrium exists only when the utilities of individuals in the two regions are equalized. To incorporate perfect mobility into the model we need to (1) specify how incomes vary within regions as populations change, so as to equalize utility across regions; (2) specify under what conditions both regions are occupied and (3) solve how population mobility affect the choice of public services.

In term of income, we assume

$$
y_{i}=A_{i} L_{i}^{-\gamma} \quad i=1,2
$$

That is to say, per capita income declines with population. This could be due to "congestion", or other 
external diseconomies. It could also be due to diminishing returns to a fixed factor, such as land, where $y_{i}$ is then the average product of labor, assuming land rents are distributed equally among regional residents. Second, we assume that net income per capita after the fixed governance costs declines with population for relevant interior solution values of $L_{i}$, so

$$
\frac{\partial\left(y_{i}-\frac{F_{i}}{L_{i}}\right)}{\partial L_{i}}=-\gamma A_{i} L_{i}^{-\gamma-1}+\frac{F_{i}}{L_{i}^{2}}<0
$$

This assumption below helps ensure stability of an interior solution of population division.

Regional governments in decision making will now take into consideration the impact of $g_{i}$ on $y_{i}$ and $L_{i}$, when they strategically choose $g_{i}$ (given $g_{j}$ ). However, under a nondiscretionary tax system, while there is an impact of $g_{i}$ on $y_{i}$ and $L_{i}$, the impacts net out and the optimal level of local public goods is still $g_{i}^{* *}$ in (7) for region $i$, given region $j$ choice (Henderson (1994)). ${ }^{15}$

Thus, utilities under unitary and federal structures are still defined by (5a), and (8), respectively. Nevertheless, the free mobility assumption imposes more structure- namely equal utilities across regions. Therefore, under a unitary government and for any level of $g$, we know that equating (3a) and (3b) results in $y_{1}^{\alpha}=y_{2}^{\alpha}(1-\delta)^{\beta}$ or an allocation of population of

$$
L_{1}=\frac{A_{1}^{1 / \gamma} L}{A_{1}^{1 / \gamma}+A_{2}^{1 / \gamma}(1-\delta)^{\frac{\beta}{\gamma \alpha}}}
$$

between the two regions. And for a federal system when $F_{2}=F$ with the free mobility, equating utilities in

\footnotetext{
${ }^{15}$ For example, under the federal structure, region 2 government chooses $g_{2}$ to maximize

$$
u_{2}=\left(y_{2}-\frac{F_{2}}{L_{2}}-g_{2}\right)^{\alpha} g_{2}^{\beta}
$$

given the value of $g_{1}$, production functions in (23), and the free mobility and full employment constraints $\left(y_{2}-F_{2 /} L_{2}-g_{2}\right)^{\alpha} g_{2}^{\beta}=$ $\left(y_{1}-F_{1} / L_{1}-g_{1}\right)^{\alpha} g_{1}^{\beta}$ and $L_{1}+L_{2}=L$. If we maximize $u_{2}$ with respect to $g_{2}$, the total derivative is $\frac{d u_{2}}{d g_{2}}=\frac{\partial u_{2}}{\partial g_{2}}+\frac{\partial u_{2}}{\partial L_{2}} \frac{\partial L_{2}}{\partial g_{2}}+$ $\frac{\partial u_{2}}{\partial y_{2}} \frac{\partial y_{2}}{\partial L_{2}} \frac{\partial L_{2}}{\partial g_{2}}$ and the first order condition is $\frac{d u_{2}}{d g_{2}}=0$. We solve for $\frac{\partial L_{2}}{\partial g_{2}}$ by differentiating the constraints and substituting the result in the first order condition. The first order condition reduces to a condition for $g_{2}^{* *}$ that is identical to the one in (7). We can repeat the analysis for $g_{1}^{* *}$, and for $g^{*}$ in (4).
} 
(8), $L_{1}$ satisfies

$$
A_{2}\left(L-L_{1}\right)^{1-\gamma} L_{1}-A_{1}\left(L-L_{1}\right) L_{1}^{1-\gamma}=F\left(2 L_{1}-L\right)
$$

Equations (25) and (26) represent population allocations under unitary and federal regimes. We only consider cases where such solutions are unique and interior.

For example, if the two regions have the same production functions, i.e. $A_{1}=A_{2}$, if an interior unique equilibrium exists, $L_{1}=L_{2}=\frac{1}{2}$ under a federal structure. Stability of the allocation follows from the assumption in (24). ${ }^{16}$ The equal population allocation emerges as an equilibrium under a unitary structure, if $\delta=0^{17}$. But, under a unitary structure, if $\delta>0$ then $L_{1}>\frac{1}{2} L$ satisfies (25), which in turn means higher income in region 2 or $y_{2}>y_{1}$ that compensates residents of region 2 for spatial decay. The question of which allocations in (25) and (26) are unique interior solutions is really beyond the scope of this paper (see for example, Pines (1991)). Here if $C_{0}$ in (5) is normalized to 1 , so $u_{i}=A_{i} L_{i}^{-\gamma}-F_{i} / L_{i}$, then if $\gamma \geq 1$ as $L_{i} \rightarrow 0$, $u_{i}>0$ and $\frac{\partial u_{i}}{\partial L_{i}}<0$. This is enough to produce an unique interior equilibrium since in both regions utility declines by size (and (26) is satisfied). If $\gamma<1$ then as $L_{i} \rightarrow 0, u_{i}<0$ and $\frac{\partial u_{i}}{\partial L_{i}}>0$. Then, for $A_{1}=A_{2}$, a well behaved unique interior solution occurs if $\frac{\partial u_{i}}{\partial L_{i}}=0$ at an $L_{i}<\frac{1}{2} L$.

With free mobility, the evaluation of a federal versus a unitary structure changes, since within a regime all citizens have equal utility ex-post. So the question reduces to whether the country, as a whole, is better off under what regime. A unitary system prevails if

$$
A_{2} L_{2}^{-\gamma}-\frac{F_{2}}{L_{2}}<\left(A_{2}\left(L_{2}^{*}\right)^{-\gamma}-\frac{F}{L_{2}^{*}+L_{1}^{*} \frac{A_{1}}{A_{2}}\left(\frac{L_{1}^{*}}{L_{2}^{*}}\right)^{-\gamma}}\right)\left(L_{2}^{*}+L_{1}^{*} \frac{A_{1}}{A_{2}}\left(\frac{L_{1}^{*}}{L_{2}^{*}}\right)^{-\gamma}\right)^{\frac{\beta}{\beta+\alpha}}(1-\delta)^{\frac{\beta}{\beta+\alpha}}
$$

where $L_{2}$ and $L_{2}^{*}$ are the population levels that respectively satisfy in (27) and (26). Note $L_{1}=L-L_{2}$.

It is easy to see that if $A_{1}=A_{2}$ and $F=F_{2}>0$ and $\delta=0$, a unitary structure dominates. Then as we showed before, $L_{1}=L_{2}$ is a stable equilibrium and $y_{1}=y_{2}$. Since the incomes are the same the demand for

\footnotetext{
${ }^{16}$ For stability, we need $\frac{\partial u_{i}}{\partial L_{i}}<0$ in the neighborhood of an interior solution. Given that $(7)$ holds, $\frac{\partial u_{i}}{\partial L_{i}}<0$ reduces to $(24)$.

${ }^{17}$ In fact, if $\delta=0$ there is no reason to have a federal system since it involves an extra costs for additional government when there is no benefits from such government.
} 
local public goods are the same in the two regions. So, a unitary regime dominates because people need only to pay for one government instead of two regional governments in a federation. Similarly, if $\delta>0$ and $F_{2}=0$ then a federal structure dominates since it is costless to form a second government which then eliminates spatial decay of public goods in region 2 .

\subsection{Summary}

Under imperfect population mobility, section 2.1 with perfect democracy suggested that separation, or adoption of formal federal structures is promoted by (1) income growth, (2) population growth, (3) higher spatial decay of local public services provided to the hinterland by the central government, (4) relative income growth in the hinterland region, (5) relative population growth in the hinterland at least when $y_{1}>y_{2}$, and (6) and lower costs of government, i.e. $F_{2}$, for the hinterland region. Section 2.2 with imperfect democracy based on an analysis of eq. (19) had the same hypotheses, plus the additional one that separation is promoted by there being a greater degree of local democratic culture, compared to the nation. In section 3, we will examine these hypotheses empirically.

\section{Empirical Formulation}

In this section, we test the hypotheses just presented in Section 2. Empirically, as we discussed in the introduction, federalism can be defined as an institutional all-or-nothing concept: does a country adopt a federal constitution, or does a county adopt a federal constitution (de jure) and also hold local elections (de facto)? We also developed an index of the degree of institutional federalism, or decentralization, for a more nuanced institutional approach. The institutional approach has the advantage of being directly connected to the model in Section 2, which asks when countries will adopt a working federal constitution.

However, in many cultural, historical, and political circumstances institutional structures are very rigid and change may involve almost unworkable political processes. In contrast fiscal structures are much more 
flexible and can be altered through legislative initiatives or even executive order. For example, of our 48 countries for which we have complete federalism data only 3 change constitution from unitary to federal or vice versa between 1975 and 1995. In contrast the degree of fiscal decentralization changes for almost all countries in that time period. Thus a unitary country which would have great difficulty altering its constitution in a twenty-year time frame can still decentralize fiscally and become de facto federalized.

Thus we also examine fiscal decentralization where there is a continuum of outcomes described by the degree of fiscal centralization, as measured by the central government's share of government consumption. For this we think of the forces towards separation that are analyzed in Section 2, as the forces that move a country across that continuum, from a high degree of fiscal centralization to a low one. In this section we examine both empirical approaches to looking at decentralization. We start with the institutional approach.

\subsection{Institutional Decentralization}

For institutional decentralization, we adopt two approaches. The primary one is to look cross-sectionally at 1995 institutional structures, as a function of 1965 country conditions. Are conditions of a country in 1965 sufficient to yield a federal institutional structure by 1995? So, the specification of our latent variable is

$$
y_{i}^{*}(1995)=\beta X_{i}(1965)+u_{i}+\varepsilon_{i}(1995)
$$

and we are modelling the probability that $y_{i}^{*}>0$ in 1995 . We define institution federalism on an all or nothing basis in two ways. First is whether a country has a federal constitution or not in 1995 and second is whether it has local or state democratic elections in addition to a federal constitution. The latter imposes a requirement of effective federalism, but however also local democratization which is a separate issue.

A key concern is the error structure. The $u_{i}$ represents a country specific effect, capturing time invariant cultural and historical aspects of country which determine "political traditions" that affect $y^{*}$, but not necessarily $X_{i}(t) \cdot \varepsilon_{i}(1995)$ are contemporaneous shocks, which potentially affect current political and economic 
outcomes. Such shocks include civil unrest, election of charismatic leaders or an ineffective assembly, a huge drop in export prices precipitating large scale temporary unemployment, etc.

The advantage of the specification in (28) is that $X_{i}$ (1965) are orthogonal to $\varepsilon_{i}(1995)$. Then if $u_{i}$ affects only political and not economic variables $\left(X_{i}\right)$, eq. (28) can be estimated by ordinary Probit. The disadvantage of the approach is that, the all or nothing institutional measure itself is time inflexible. There is considerable effective fiscal decentralization and development of local democratic institutions between 1975 and 1995. We do have a nuanced index of "institutional" decentralization, or effective federalism, that combines information on the constitution, state elections, local elections, ability of the center to suspend lower levels of government, local revenue raising authority, and revenue sharing (see Appendix). That changes for 31 of 48 countries between 1975 and 1995.

For the federalism index, as a second approach, we pool the data for 1975, 1985, and 1995 and estimate a random effects model where

$$
y_{i}(t)=\beta_{i} X_{i}(t-1)+u_{i}+\varepsilon_{i}(t)
$$

This formulation is also the one we use in the next section when examining fiscal decentralization. So it is worth detailing estimation issues. In eq. (29) we use 10-year time intervals for $y_{i}(t)$ and lag covariates 5 years, ${ }^{18}$ to allow for a time lag for the federal institutions to adjust to current economic conditions.

Estimation of eq. (29) (and of course eq. (28)) is subject to measurement error, for example, in income. Second, rather than a simple random effects structure, we may more generally have serially correlated errors where the $\varepsilon_{i}(t)$ that affects both $y_{i}(t)$ and $X_{i}(t)$ is also still correlated with the $X_{i}(t-1)$ from 5 years ago. Accordingly we try instrumental variables estimation using 1965 values of economic and demographic variables as instruments, as well as cultural and geographic variables that we introduce later. Why are historical values of economic, demographic and geographic variables strong instruments? As part of the economic growth process, past values of income investment, education, life expectancy and the like are

\footnotetext{
${ }^{18}$ This will allow us to instrument with 1965 variables for 1970 variables in the 1975 equation.
} 
significant determinants of future income and population. Fstatistics of first stage regressions for our basic economic and demographic covariates are all over 150. Using instrumental variables, we do 2SLS, 3SLS, and GMM, with modest differences in results. The GMM estimators adjust 3SLS coefficients for within period heteroskedasticity. ${ }^{19}$ We report just the GMM estimates.

We also tried fixed effects estimation. Such estimates are plagued by measurement error and all coefficients are insignificant and, as such, a random effects formulation (Hausman test) can't be rejected in favor of fixed effects. One could also time difference the data (to remove the fixed effect), and instrument with predetermined values of variables. It seems that the first differences are heavily dominated by measurement errors. Instruments turn out to be very weak and we don't pursue this approach.

\section{$\underline{\text { Results }}$}

Table 1 presents the results on the institutional federalism. We focus on four explanatory variables that are related to the hypotheses summarized in section 2.4.: income, national population, national land area and size of the largest metro area The first two have a direct interpretation in the model in Section 2. The third, national land area, represents the degree of spatial dispersion and decay of central public services to regions, a key element to the model. In Section 2, another key element is the relative population in the coastal versus hinterland regions. We have no direct measure of that, but we know urban primacy in developing countries is critical. Many countries are dominated by a primate city, often the national capital, which is typically in the dominant region. Urban primacy is often viewed as a measure of central political control (Ades and Glaeser (1995), Henderson (2000)), and as being correlated with the degree of regional income inequality. Here we use it to approximate the relative degree of population and economic centralization. We have two measures yielding similar results - urban primacy (population of the largest metro area divided by national urban population) and the absolute population size of the largest metro area. Given we control in the model for national population (and income), we choose just to present results for the latter; those for primacy are similar (Arzaghi and Henderson (2002)). We also have cultural measures from Easterly and Levine (1997)

\footnotetext{
${ }^{19}$ We use the Arelleno and Bond (1991) estimator, utilizing their Gauss program (DPD98).
} 
and whether the country has a French Law tradition (as opposed to British Law for most other countries). For the degree of local versus national degree of democratization we do have some measures, but for reasons to be discussed later we wait to the next section to introduce them. Definitions and details for all measures are in the Data Appendix.

The basic results are in columns 1-3, where we have three measures of institutional federalism. The first two are discrete: either a country is federal or not. The first (column 1) is simply whether a country has a federal constitution in 1995. The second requires a country to both have a federal constitution in 1995 and to have operational either provincial/state or local level elections. The third is the effective federalism index described earlier. Note sample sizes are small, 41 countries, which limits the degree of precision we can expect.

We start with columns (1) and (2). Sign patterns support our hypotheses. As income rises the probability of adopting a federal institutional structure rises. The income effects are enormous and significant. To illustrate magnitudes, we focus on the results in column (1). From a base probability (evaluated at average values of covariates) of .18 of having a federal structure, a one-standard deviation increase in income raises the probability to .63 in column (1). Similarly land effects are enormous and significant, where greater land area and hence spatial dispersion, increases the likelihood of being federal. From the base probability of .18 in column (1), a one-standard deviation increase in land raises the probability of being federal to .60. The effects of national population and size of the largest metro area have expected signs but are insignificant. But evaluated at point estimates of the coefficients, these variables would also have big effects, with a onestandard deviation increase in national population and decrease in metro area population respectively raising the probability from the base of .18 to .48 and .55 . These results are consistent with the Section 2 hypotheses.

The column (3) results on the federal index are less precise. Only income has a significant effect. To try to increase precision, we exploit time variation in the data on that variable. The random effect results in column (4) for 1975, 1985, and 1995 pooled based on lagged covariates are very similar to the 1995 results in column (3) based on historical values - only income is significant again and coefficients are similar. 
However the GMM estimation in column (5) is very different, indicating issues of measurement error and simultaneity bias may be important. Income, national population and national land area all have significant and much larger effects. From an average index value of 1.44, a one-standard deviation increase in income, national population and land increase the index by respectively $1.08, .53$, and .25 . While metro area size is insignificant, its sign is now as hypothesized; and the point estimate is large. The p-value for the Sargan specification test on the overall model and validity of instruments is satisfactory, as in all models tested in this paper, but not as high as one would like. Fortunately, there is no evidence of serial correlation, which helps.

In the formulations in Table 1, we experimented with our cultural variables on ethnolinguistic diversity and French Law but neither are ever significant at the 5\% level. French Law usually has a negative size (Paris as the ultimate central system historically); and ethnolinguistic diversity has a positive sign, reflecting the idea that federal constitutions arise when intra-national (i.e., region) tastes differ. After controlling for these two cultural variables, sample sizes are too small to identify separately effects of being a Muslim nation, or a majority Catholic nation. For local versus national democracy, since two of our dependent variables contain aspects of local democracy, we didn't think this was the right context to test effects. But it will be discussed in detail in the next section.

\subsection{Fiscal Decentralization}

We construct a fiscal centralization measure which is the share of the central government in total government consumption expenditures. It reflects the forces modeled in Section 2 - the push to or from greater local autonomy, or independence. As noted earlier there are few constitutional changes in our sample from 1975 to 1995, but de facto shifts occur as measured by the degree of fiscal (de)centralization. As such, our basic model will be eq. (29) where there is a new dependent variable. However with a more flexible dependent variable, covariates are not lagged but are contemporaneous. Given that, IV estimation will be even more critical. With the more flexible dependent variable, results will be sharper and ethnolinguistic variables 
significant.

This framework is also a better context to examine the effects of local versus national democratization. So, after examining results corresponding to those for institutional decentralization we will turn to trying to control for and compare the effects of national versus local democratization. However this raises an alternative issue.

Perhaps the degree of fiscal decentralization depends on the constitutional structure per se. Moreover the effect of income and other covariates on fiscal decentralization may depend on "regime", or constitutional structure. We have a limited sample size and measures, but we experimented with this idea extensively and reject at least the idea that the effects of economic and demographic variables differ by regime. In particular in the basic random effect results in columns (1) and (2) in Table 2 below, with all variables included coefficients are not significantly different for federal countries versus non-federal countries. Specifically, a dummy variable for whether a country has a federal constitution in 1975 and that variable interacted with the covariates, all have insignificant coefficients ${ }^{20}$ while the basic covariates remain significant except for land. Moreover, treating the problem as additionally one of sample selection yielded for both sides completely insignificant coefficients on Mills' ratios in a Heckman selection specification. ${ }^{21}$ We proceed with the idea that our fiscal centralization measure reflects in itself the degree of local fiscal and political autonomy, without regime switching based on the constitution. But we return to the issue later on.

\section{$\underline{\text { Results }}$}

The primary specification is for the four economic-geography variables in Table 1 plus cultural variables. Results are in Table 2 for both random effects and GMM estimation. There is an issue in estimation of truncation. Six of 52 countries in the sample always have $100 \%$ centralization. Results with them excluded in the sample and included in regular random effects, a random effects Tobit and GMM are similar for the corresponding cases (see Arzaghi and Henderson (2002)). Accordingly we report the set of results with those

\footnotetext{
${ }^{20}$ The maximum t-statistic on any of these variables is 1.27 . For smaller countries (under $10 \mathrm{~m}$ people) we didn't have the data on federal constitution, so we used whether a country had local or state elections in 1975 or not as defining federal.

${ }^{21}$ Maximum likelihood versions were not well behaved with the small sample sizes.
} 
six countries excluded.

In Table 2, we focus on the IV results in column (4). IV results are generally stronger, especially for population related variables. In column (4), the basic variables from Table 1 have expected signs and are all significant. Noting that the mean share of central government consumption is about .60, a one-standard deviation increase in income lowers the share by .11, in national population lowers the share by .20, in population of the largest metro area ("coastal" region centralization) raises the share by .21, and in national land area lowers the share by .10. These are all substantial effects. In terms of cultural influences, French Law has a strong positive effect on centralization.

However, ethnolinguistic diversity also increases fiscal centralization. While in Section 2 ethnolinguistic diversity led to a greater likelihood of having a federal constitution (albeit the coefficient was insignificant), here it increases centralization. This is consistent with results in Easterly and Levine (1997) and Laporta et al. (1998). Diverse countries may choose to remain de facto centralized as a strong-arm way of avoiding a complete split of the country into two (or more). The idea is that fiscal decentralization breeds calls for regional independence and a new country (e.g. Quebec in Canada). An alternative and very different explanation would be the idea of a centralized majority/plurality population exploiting the hinterlands through centralization regardless of the constitution.

Local Democracy and Regime Switches. In the model in Section 2, we indicated that differing effective degrees of "inherent" democracy between the national and regional governments would influence decentralization. An increase in local democracy would enhance decentralization while an increase in national democracy would make decentralization less beneficial. We have no measure of inherent democracy, let alone relative regional versus national degrees of inherent democracy. We have Jaggers and Gurr's (1995) Polity III indicator of national democratization, which measures the extent of current effective democratization nationally. That surely reflects inherent democratization, updated by evolving economic and demographic conditions. But national legislative and executive democratization also reflect the development of representative government, awakening of regional representation nationally, and potentially the development of 
regional power bases and politics. As noted in the introduction, the index of democratization and federalism are strongly correlated, reflecting in part this link between national democratization and development of regional politics.

We can't really test our hypothesis concerning inherent national versus local democracy as formulated in Section 2. Instead we investigate two other alternative specifications. First we argue that having a federal constitution in place per se encourages fiscal decentralization, although as explained earlier it doesn't appear to affect the degree of influence of the covariates on fiscal decentralization. In column (1) and (3) of Table 3 for random effects and IV estimation having a federal constitution lowers the central government's share of government consumption by respectively .14 and .20 (from an average of .60). Thus in the model in Section 2 effective "separation, or development of regional fiscal autonomy is helped by conducive institutional frameworks.

Second, we compare the effects of having local elections or not in 1975 versus the degree of national democratization in $1975 .{ }^{22}$ We could be using these as proxies for inherent national and local democracy, instrumenting with historical variables concerning historical economic and demographic conditions, culture, geography, and whether the country had a federal constitution or not in $1965 .^{23}$ In the IV estimation in column (4), having local elections in 1975 has no effect on fiscal decentralization, whereas national democratization helps. More specifically having local elections with no control for national democratization has a strong significant negative coefficient as expected; however introducing national democratization wipes out this effect. This would contradict Section 2 hypotheses with the caveat that we are not instrumenting for a discrete covariate in an efficient manner. However a different interpretation would be that the national democratization variable is the key control, reflecting the development of regional representation and politics. We note that the simple correlation coefficient between having local elections (discrete) and the democratization index is .54. The degree of national democratization also reflects the development of local

\footnotetext{
${ }^{22}$ Actually the latter measure is the average of the 1970-74 III Polity III index for a country.

${ }^{23}$ For a few small countries where we don't have information federal constitution we use the criterion as to whether they had local election or not in 1975.
} 
elections.

Column (5) explores the idea that fiscal decentralization is encouraged both by having a federal constitution, (institutional framework for "separation"), and by the development of national democracy and representative government. The results support this idea. These suggest an alternative model to the one in section 2 where the development of regional politics and demand for autonomy evolves from national democratization.

\section{Conclusion}

In this paper we develop and test a simple model of fiscal decentralization within a country. We hypothesize that basic economic and demographic variables explain most of the observed variation in the degree of institutional and fiscal decentralization across countries. We find that income per capita, population, land area, and the degree of population concentration in the largest (typically capital) city in a country, have large effects on the degree of decentralization. Income and population growth lead to decentralization, as does population decentralization. The degree of centralization in countries is largely explained by simple economic and demographic growth processes. However at the end we argue that institutions affect fiscal outcomes. Having a federal constitution encourages both effective federalism and fiscal decentralization. And national democratization leads to potentially regional representation and the development of regional demands for greater fiscal autonomy. 


\section{References}

Ades, Alberto F. and Edward L. Glaeser (1995), "Trade and Circuses: Explaining Urban Giants", Quarterly Journal of Economics, 110 (1), pp. 195-227.

Alesina, Alberto, Roberto Perotti, and Enrico Spolaore (1995), "Together or Separately? Issues on the Costs and Benefits of Political and Fiscal Unions." European Economic Review, 39, pp. 751-758.

Alesina, Alberto, and Enrico Spolaore (1997), "On the Number and Size of the Nations." Quarterly Journal of Economics, 112(4), pp. 1027-1056.

Alesina, Alberto and Enrico Spolaore (2003), The Size of Nations, forthcoming.

Arellano, Manuel, and Stephen Bond (1991), "Some Tests of Specification for Panel Data: Monte Carlo Evidence and an Application to Employment Equations." The Review of Economic Studies, 58(2), pp. 277-297.

Arellano, Manuel, and Stephen Bond (1998), "Dynamic Panel Data Estimation Using DPD98 for Gauss: A Guide for Users." Institute for Fiscal studies webpage.

Arzaghi, M. and J.V. Henderson (2002), "Why Countries Are Fiscally Centralizing", (URL:http://www.econ.brown.edu/faculty/henderson/papers/decent402.pdf)

Barro, Robert J., and Jong W. Lee (1996), "International Measures of Schooling Years and Schooling Quality." American Economic Review, 86(2), pp. 218-223.

Besley, Timothy and Stephen Coate (1999), "Centralized versus Decentralized Provision of Local Public Goods: A Political Economy Analysis", NBER 7084.

Bolton, Patric, and Gerard Roland (1997), "The Breakup of Nations: A Political Economy Analysis." Quarterly Journal of Economics, 112(4), pp. 1057-90.

Bolton, Patric, Gerard Roland, and Enrico Spolaore (1996), "Economic Theory of the Break up and Integration of Nations." European Economic Review, 40(3-5), pp. 697-706.

Buchanan, James M., and Roger L. Faith (1987), "Secession and the Limits of Taxation: Toward a theory of internal exit." American Economic Review, 77, pp.1023-31.

Easterly, William and Ross Levine (1997), "Africa's Growth Tragedy: Policies and Ethnic Divisions", QJE, $112,1203-1250$.

Friedman, David (1977), "A Theory of the Size and Shaper of Nations." Journal of Political Economy, 85, pp. 59-77.

Henderson, Vernon (1994), "Community Choice of Revenue Instruments." Regional Science and Urban Economics, 24, pp. 159-184.

Henderson, Vernon (2000), "The Effects of Urban Concentration on Economic Growth." NBER 7503.

Hochman, Oded, David Pines, and Jacques F. Thisse (1995), "On the Optimal Structure of Local Governments." American Economic Review, 85(5), pp. 1224-1240.

International Monetary Fund (IMF), "Government Finance Statistics Yearbook (GFS)." Washington D.C.: IMF, annual publication. 
Jaggers, Keith, and Ted R. Gurr (1995), "Tracking Democracy's Third Wave with the Polity III Data." Journal of Peace Research, 32(4), pp. 469-482.

Jaggers, Keith, and Ted R. Gurr (1996), "Polity III: Regime Changes and Political Authority, 1800-1994. Second ICPSR Version." ICPSR 6695.

La Porta, Rafael, Florencio Lopez-de-Silanes, Andrei Shleifer, and Robert Vishny (1998), "The Quality of Government." NBER 6727.

Musgrave, Richard A. (1959), "The Theory of Public Finance." New York: McGraw-Hill.

Musgrave, Richard A. (1969), "Theories of Fiscal Federalism." Public Finance, 24(4), pp. 521-532.

Oates, Wallace E. (1972), "Fiscal Federalism." New York, NY: Harcourt Brace Jovanovich, Academic Press.

Oates, Wallace E. (1981), "On Local Finance and the Tiebout Model." American Economic Review, 71, pp.93-98.

Oates, Wallace E., and John J. Wallis (1988), "Decentralization in the Public Sector: An Empirical Study and Local Governments." in "Fiscal Decentralization: Quantitative Studies" edited by Harvey S. Rosen, NBER Project Report, Chicago and London: University of Chicago Press.

Osborne, Martin J., and Ariel Rubinstein (1990), "Bargaining and Markets." San Diego; London; Sydney; and Toronto: Harcourt Brace Jovanovich, Academic Press..

Osborne, Martin J., and Ariel Rubinstein (1994), "A Course in Game Theory." Cambridge and London: MIT Press.

Panizza, Ugo (1999), "On the Determinants of Fiscal Centralization: Theory and Evidence." Journal of Public Economics, 74, pp. 97-139.

Persson, Torsten, Gerard Roland, and Guido Tabellini (1996), "The Theory of Fiscal Federalism: What Does It Mean for Europe?" IGIER.

Persson, Torsten, and Guido Tabellini (1996), "Federal Fiscal Constitutions: Risk Sharing and Redistribution." Journal of Political Economy, 104, pp. 979-1009.

Persson, Torsten, and Guido Tabellini (1996), "Federal Fiscal Constitutions: Risk Sharing and Moral Hazard." Econometrica, 64, pp. 623-646.

Pines, David (1991), "Tiebout Without Politics." Regional Science and Urban Economics, 21, 496-489.

Polo, Michele (1998), "Electoral Competition and Political Rents." IGIER.

Starrett, David A. (1980), "Measuring Externalities and Second Best Distortions in the Theory of Local Public Goods." Econometrica, 48(3), pp. 627-642.

Summers, Robert, and Alan W. Heston (1991), "The Penn World Table (Mark 5): An Expanded Set of International Comparisons 1950-1988." Quarterly Journal of Economics, 106, pp. 327-68.

Summers, Robert, and Alan W. Heston (1995), "Penn World Table Mark 5.6 revision of Summers and Heston (1991) on-line data." Computing in the Humanities and Social Sciences (CHASS), Toronto: University of Toronto.

Tiebout, Charles (1956), "A pure theory of local expenditures." Journal of Political Economy, 64, pp. 416-424. 
Tiebout, Charles (1961), "An Economic Theory of Fiscal Decentralization." NBER, Public Finance: Needs, Sources and Utilization.

United Nations, "World Urbanization Prospects: The 1998 Revision." United Nations Population Division, Department for Economic and Social Information and Policy Analysis, New York, 1998.

World Bank, "World Development Indicators (WDI) on CD-Rom." Washington D.C.: World Bank.

Wittman, Donald (1989), "Why Democracies Produce Efficient Results." Journal of Political Economy, 97, pp. 1395-1424.

Wittman, Donald (1991), "Nations and States: Mergers and Acquisitions: Dissolution and Divorce." American Economic Review, 81, pp. 126-129. 


\section{Data Appendix}

Here we discuss the key variables that we used in the introduction and in our empirical work. The measures of fiscal centralization and of federalism were constructed for this paper. We pay more attention to those variables in this appendix since their construction is not routine in the literature. We also will provide a brief description of other variables, such as the land area, regional dummies, and GDP per capita, which have standard definitions and come from standard sources, and are routinely used in literature.

The data ${ }^{24}$ that are used in this study are a collection of all the important socioeconomic characteristics of about $190^{25}$ countries around the world. The data are from a variety of sources. ${ }^{26}$ The data cover 40 years time span from 1960 to 1995 in five years intervals; however, many of the variables are only available since 1970 .

\section{General variables}

- GDP per capita: Real GDP per capita is in constant 1985 dollars from Penn World Tables Mark 5.6. The Penn World Tables coverage ends on 1992. The figures for 1995 are extrapolated form 1992 values using World Bank WDI real GDP per capita growth figures for 1992-1995. Values are missing for West Germany, Czechoslovakia, Yugoslavia and USSR in 1995.

- Land: Land area is in square kilometers from World Bank WDI. Values for West Germany, Czechoslovakia, Yugoslavia and USSR are taken from the Columbia Encyclopedia.

\footnotetext{
${ }^{24}$ The dataset has been put together during the past 5 years by Jim Davis, under provision of Vernon Henderson at the Department of Economics of Brown University. It is available on Vernon Henderson's website at the Department of Economics' webpage.

${ }^{25}$ While some of the variables, such as land area and population, are available for all 190 countries since 1960, other more important variables, such as GDP pre capita, are only available for the subset of the data. For example, only 150 countries have GDP figures for at least one year. The detail of data availability will be discuss for important variables separately.

${ }^{26}$ Barro, Robert J. and J. W. Lee, International Measures of Schooling Years and Schooling Quality on-line data, World Bank Economic Growth Research Group, Washington D.C.: World Bank, 1996.

Freedom House, Freedom in the World, New York: Freedom House, various years.

International Monetary Fund (IMF), Government Finance Statistics (GFS), Washington D.C.: International Monetary Fund, various years.

Summers, R., and A. Heston, Penn World Table Mark 5.6 version of Summer and Heston (1991) on-line data, Computing in the Humanities and Social Sciences (CHASS), Toronto: University of Toronto, 1995.

United Nations, World Urbanization Prospects: The 1998 Revision, United Nations Population Division, Department of Economics and Social Information and Policy Analysis, New York, 1998.

World Bank, World Development Indicators (WDI) on CD-ROM, Washington D.C.: World Bank, 1998.
} 
- Population: Total national and urban populations are from United Nations World Urbanization Prospects: The 1998 Revision, Table A.12 and Table A.5, respectively. Values for West Germany, Czechoslovakia, Yugoslavia and USSR are taken from the Penn World tables 5.6.

- Population of largest metro area: Population of largest city is from United Nations World Urbanization Prospects: The 1998 Revision, Table A.3.

- Investment: It is the percentage share of real investment in GDP from Penn World Tables Mark 5.6. We use a five year average of the shares, e.g. the value for 1965 is an average over 1960-1964.

- Life expectancy: Life expectancy at birth in years is from World Bank WDI. Czechoslovakia, Yugoslavia and USSR are averages over the constituent republics weighted by population share. The values for united Germany are substituted for West Germany. We use a five year average values, e.g. the value for 1965 is an average over 1960-1964.

- Schooling attainment of women: It is the average years of high school and collage in the female population aged 25 and over from Barro and Lee (1996). Census and survey figures primarily from UNESCO Statistical Yearbooks and UN Demographic Yearbooks fill two fifths of the observations. The remaining values are estimated using UNESCO school enrollment data and a perpetual inventory method. The data are not adjusted for quality of education or length of school day or year.

- Latitude: This variable is from La Porta et. al. (1998).

- We tried some other variables from La Porta et. al. (1998) to control for cultural and legislative differences, such as adopting English Common Law or French commercial code, and so on. We also have a measure of ethnolinguistic fractionalization which is an index from Easterly and Levine (1997) averaging five indices representing (a) the probabilities that any two randomly chosen people in a country (1) come from a different ethnic group, (2) speak different languages, and (3) do not speak the same language, and (b) the percent of the population not speaking (1) the official language, and 
(2) the most widely used language.

Fiscal centralization measures Three different measures of fiscal centralization are constructed. The variables are based on the Government Finance Statistics Yearbook (GFS) figures for national, state, and local governments consolidated expenditures. The first measure $\left(m e_{1}\right)$ is the share of the central government in general government (all levels of government together) total expenditures plus net lending. It includes all kind of expenditures, such as capital investment, and inter-governmental transfers. In the older volumes of GFS (before 1986), the total expenditure for the central government and general government ${ }^{27}$ were readily available for countries around the world ${ }^{28}$ in the summary tables. So, values of $m e_{1}$ are available for 1975 and 1985 after simple calculation. This variable is widely used in previous empirical studies ${ }^{29}$ and we extend it to include 1995. We use a following formula to calculate this measure consistently for 1975, 1985, and 1995.

$$
\begin{aligned}
m_{1}= & \frac{C_{1}}{G_{1}} \\
C_{1}= & \text { Central }(\text { C.I }) \\
G_{1}= & \text { Central }(\text { C.I })-\text { Central }(\text { C.III.3.2 })-\text { Central }(\text { C.IV.7.1.1 })-\text { Central }(\text { C.V.8.1 }) \\
& + \text { St }(\text { C.I })-\text { St }(\text { C.III.3.2) }- \text { St }(\text { C.IV.7.1.1 })-S t(C . V .8 .1) \\
& +L(C . I)-L(\text { C.III.3.2 })-L(\text { C.IV.7.1.1 })-L(C . V .8 .1)
\end{aligned}
$$

The C.I, C.III.3.2, and so on refer to different items of Table C of GFS. St and $L$ stand for state/provincial and local government, respectively. We compared the measures for 1975 and 1985 with the one calculated from the summary tables and the results were indistinguishable.

The second measure is the share of the central government in general government consumption expendi-

\footnotetext{
${ }^{27}$ General government expenditures are a consolidated sum of expenditures for all the government tiers. Consolidation is important since it prevents double counting of inter-governmental grants and transfers.

${ }^{28}$ The data cover more than 100 countries, however not all of them have information for all the years.

${ }^{29}$ Both Panizza and Oates use this variable. They look at revenue side of government accounts, too. They show that there is a little difference in results using revenue measures.
} 
tures. It emphasizes current expenditures on goods and services by governments. So, investment, interest payments, and social security expenditures are excluded. It is calculated using item C.III.1 in Table C for different levels of government for each country.

$$
\begin{aligned}
m e_{2} & =\frac{C_{2}}{G_{2}} \\
C_{2} & =\text { Central }(\text { C.III.1 }) \\
G_{2} & =\text { Central }(\text { C.III.1 })+\text { St }(\text { C.III.1 })+L(C . I I I .1)
\end{aligned}
$$

In a sense, it is the most direct measure that we have and we rely on this measure in our empirical work.

The third measure is the same as the second measure except that capital expenditures are included. So, we use C.III.1 + C.IV.4-6 as an expenditure measure.

The number of countries with enough information to calculate each measure varies over the years. The first measure can be calculated for more countries than the two other measures, but it also is prone to more error caused by missing values of minor items in the calculation of $G_{1}$. It is available for 62,53 , and 53 countries in 1975, 1985, and 1995, respectively. The second and third measures are available for 39, 47, and 49 countries in those years. The second and third measures are profoundly correlated, with correlation of 0.99 in levels and 0.97 in first differences. The correlation between the first and second measure is also high at about 0.74 . However, this correlation drops to 0.22 when we look at the first differences.

Democracy variable The democracy variable is from Polity III (ICPSR 6695 data set). It comprises two main indicators: autocracy and democracy, which capture different aspects of political authority and regime type. Polity III covers 177 nations; among them 20 have historical data that go back to 1800 . However, we are only interested in data since 1960. Annual indicators of institutional autocracy and democracy are available for $122,135,135$, and 151 states in $1965,1975,1985$, and 1994, respectively. It covers all of the countries in our database with available federalism or centralization measures. Each indicator is a value form 0 to 10 . The 
value of each indicator for a country is the sum of the score of that country in the following five categories: (1) Competitiveness of Political Participation, (2) Regulation of Political Participation, (3) Competitiveness of Executive, (4) Openness of Executive Recruitment, (5) Constraints on Chief Executive. Most of the literature relies on a single measure of democracy, which is defined as OVERALL DEMOC=DEMOC-AUTOC, as a reasonable measure of overall democracy. We construct and use a five year average of the annual data, e.g. the value use for 1985 is an average of 1981-1985 values. The correlation between the overall measure and the institutional democracy indicator is as high as 0.98 for our five years average in our sample. For more information we refer the reader to Jaggers and Gurr (1996), which includes a detailed description of data and its code book, and to Jaggers and Gurr (1995), which defines components of the Polity III indicators and provides a detailed descriptive analysis of them and their trends.

Federalism variable The federalism variable is constructed based on an assignment of fiscal, political, and administrative responsibilities of subnational governments. It is calculated for 49 countries with population above 10 million in 1990 at five year intervals from 1960 to 1995 . However, we use only 48 countries since the measure for Peru only exists for 1990 and 1995. It includes six aspects of federalism: (1) official federal versus unitary government structure, (2) election of a regional executive, (3) election of a local executive, (4) ability of the center to suspend lower levels of government or to override their decisions, (5) no, limited, or full revenue raising authority of lower levels governments, and (6) revenue sharing. Items (1) - (4) take a value of either 0 or 4 ; items (5) and (6) take values of 0,2 , or 4 . Five has a zero if neither state nor local governments have revenue raising authority, a two if one or the other does, and a four if both do. Six has a value four if both lower levels of government regularly and unconditionally receive a share of national revenues, a two if only one level receives such monies or if one or both have no discretion over how monies are spent, and a zero if neither receive monies or neither have discretion over how transfers are spent. The federalism index is a simple average of the scores. Comparing the components of the federalism and democracy measures indicates that there must be some degree of interdependence between the variables by construction. As we 
mentioned in the introduction, the correlation is 0.63 and the correlation between the first differences is 0.39 . There is some problem with truncation specially at 0 (lower bound). Out of 48 countries, 5 countries stay at zero for the whole time period. And 19 countries (including the ones at 0 ) do not change their level of federalism during 1960-1995 period. The countries tend to stay at same level for long time. There is no change in the level of federalism over 5 year intervals for about 81 percent of the sample. The data were constructed by Christine Kearney under supervision of Vernon Henderson in 1999. The data are available on request.

Regional Democracy. This variable indicates whether the state/provincial government is elected or not. For 49 countries with population over 10 million, it is the second component of the federalism index. We extend this component to 30 other countries for 1975, 1985, and 1995, using the Europa World Year Book, 2001, The Stateman's Yearbook 2002, Freedom in the World 1978 by R. Gastil, and Freedom in the World 1995-96 from Freedom House. 
Table 1. Federalism

Federal in 1995 as a function of 1965 variables $^{1}$

Federal Constitution Federal Constitution Federalism index

$\begin{array}{lc}\ln (\text { GDP per capita }) & 1.33^{* *} \\ & (0.627) \\ \ln (\text { national population) } & 0.761 \\ & (0.536) \\ \ln \text { (pop. of largest metro area) } & -0.927 \\ & (0.646) \\ \ln \text { (national land area) } & 0.782^{* *} \\ & (0.317) \\ \text { constant } & -62.2^{* *} \\ & (31.3)\end{array}$

time dummies

$\mathrm{N}$

Pseudo $\mathrm{R}^{2}$

Sargan $\rho$-value
$(1)$

(2) and Local Elections

$3.78^{*}$
$(2.15)$
1.66
$(1.26)$
-1.80
$(1.52)$
$2.05^{* *}$
$(0.981)$
$-22.27^{* *}$
$(7.93)$

n.a.

41

0.416 n.a.

41

0.697
(3)

$$
\begin{gathered}
0.734^{* *} \\
(0.253) \\
0.197 \\
(0.290) \\
0.092 \\
(0.325) \\
.0146 \\
(0.142) \\
-8.35^{* *} \\
(2.67)
\end{gathered}
$$

n.a.

41

0.421
Contemporaneous federalism index as a function of lagged covariates

$$
\text { (4) }
$$

(5)

\section{Random Effects IV Estimation}

$$
\begin{gathered}
0.654^{* *} \\
(0.140) \\
0.173 \\
(0.184) \\
0.0878 \\
(0.209) \\
0.115 \\
(0.098) \\
-8.05^{* *} \\
(1.63) \\
\\
\text { yes } \\
131[47] \\
0.511
\end{gathered}
$$$$
1.08^{* *}
$$$$
(0.124)
$$$$
0.483^{* *}
$$$$
\text { (0.213) }
$$$$
-0.303
$$$$
(0.250)
$$$$
0.196^{* *}
$$$$
(0.0773)
$$$$
-12.45^{* *}
$$$$
\text { (1.39) }
$$$$
\text { yes }
$$

** Significant at $5 \%$ level; ${ }^{*}$ significant at $10 \%$ level. Standard errors are in parentheses.

1. For the overall federalism sample the means [and standard deviations] of $\ln$ (GDP per capita), $\ln$ (national population), $\ln$ (population of largest metro area), and $\ln ($ land), are respectively 7.6 [0.95], 10.1 [1.16], 7.6 [1.12], and 13.5 [1.33].

2. Instruments are $\ln ($ land area), $\ln (\mathrm{GDPpc}$ in 1965), $\ln$ (national population 1965), $\ln$ (population of largest metro area in 1965), investment rate 1965, life expectancy in 1965, average years of high school for women 1965, latitude, ethnolinguistic diversity, and French Law. 
Table 2. Share of Central Government in Total Government Consumption

\section{Random Effects}

$\ln ($ GDP per capita)

$\ln ($ national population)

$\ln$ (pop. of largest metro area)

$\ln ($ national land area)

ethnolinguistic diversity

French Law (or not)

constant

time dummies

$\mathrm{N}$ [countries]

Overall $\mathrm{R}^{2}$

Sargan p-value

\section{(1)}

$-0.152^{* *}$

$(0.0271)$

$-0.0928^{* *}$

$(0.0367)$

$0.0964^{* *}$

(0.0437)

$-0.0323$

(0.0192)

(1)

$53^{*} *$

$2.53^{* *}$

(0.321)

yes

103 [47]

0.486
(2)

$-0.103^{* *}$

(0.0276)

$-0.109 * *$

(0.0347)

0.119 **

(0.0453)

$-0.0493^{* *}$

(0.0165)

$0.315^{* *}$

(0.114)

$0.145^{* *}$

(0.0432)

$2.17^{* *}$

(0.296)

yes

99 [45]

0.638

\section{Instrumental Variables ${ }^{2}$ (GMM)}

$$
\text { (3) }
$$

$-0.218^{* *}$

$(0.0245)$

$-0.112^{* *}$

$(0.0400)$

$0.138^{* *}$

$(0.0526)$

$-0.0583^{* *}$

$(0.0141)$

(4)

$-0.116^{* *}$

$(0.0281)$

$-0.155^{* *}$

(0.0408)

$0.207^{* *}$

(0.0592)

$-0.0613^{* *}$

(0.0132)

$0.364^{* *}$

(0.113)

$0.134^{\text {** }}$

(0.0321)

$2.17^{* *}$

(0.361)

(0.282)

$$
\text { yes }
$$

0.214

** Significant at $5 \%$ level; ${ }^{*}$ significant at $10 \%$ level. Standard errors are in parentheses.

1. The means [and standard deviations] for this sample of $\ln ($ GDP per capita), $\ln ($ national population), $\ln$ (population of largest metro area), $\ln$ (national land area), ethnolinguistic diversity, and French Law are respectively 8.6 [0.91], 9.8 [1.32], 7.8 [1.00], 12.8 [1.67], .26 [.26], and .42.

2. See footnote 2 of Table 1 for instruments. 
Table 3. Federal Institutions, Democratization and Fiscal Decentralization

\begin{tabular}{|c|c|c|c|c|c|}
\hline \multirow{3}{*}{$\ln ($ GDP per capita $)$} & \multicolumn{2}{|c|}{ Random Effects } & \multicolumn{3}{|c|}{$\begin{array}{c}\text { Instrumental Variables } \\
\quad(3)\end{array}$} \\
\hline & $-0.137^{* *}$ & $-0.0728^{* *}$ & $-0.179 * *$ & $-0.118^{* *}$ & $-0.114^{* *}$ \\
\hline & $(0.0281)$ & $(0.0349)$ & $(0.0250)$ & $(0.041)$ & $(0.0390)$ \\
\hline \multirow[t]{2}{*}{$\ln ($ national population) } & $-0.0820^{* *}$ & $-0.0761^{* *}$ & $-0.107^{* *}$ & $0.0876^{* *}$ & $0.0616^{* *}$ \\
\hline & $(0.0366)$ & $(0.0356)$ & $(0.0286)$ & $(0.0467)$ & $(0.0360)$ \\
\hline \multirow[t]{2}{*}{$\ln$ (pop. largest metro area) } & $0.0970^{* *}$ & $0.0764^{*}$ & $0.149^{* *}$ & $0.117^{*}$ & $0.0976^{* *}$ \\
\hline & $(0.0430)$ & $(0.0436)$ & $(0.0421)$ & $(0.0619)$ & $(0.0461)$ \\
\hline \multirow[t]{2}{*}{$\ln ($ national land area) } & -0.0149 & $-0.0328^{*}$ & -0.0263 & $-0.0506^{* *}$ & $0.0323^{*}$ \\
\hline & $(0.9214)$ & $(0.0179)$ & $(0.0176)$ & $(0.0162)$ & $(0.0173)$ \\
\hline \multirow[t]{2}{*}{ federal constitution in 1975} & $-0.141^{*}$ & & $-0.195^{* *}$ & & $-0.168^{* *}$ \\
\hline & $(0.081)$ & & $(0.0599)$ & & $(0.0654)$ \\
\hline \multirow[t]{2}{*}{ local elections in 1975} & & $-0.123^{*}$ & & -0.0349 & \\
\hline & & $(0.0705)$ & & $(0.115)$ & \\
\hline \multirow[t]{2}{*}{ democracy index in 1975} & & $-.0127^{*}$ & & $-0.0345^{* *}$ & $-0.0274^{* *}$ \\
\hline & & $(0.0075)$ & & $(0.0167)$ & $(0.0118)$ \\
\hline time dummies & yes & yes & yes & yes & yes \\
\hline $\mathrm{N}$ [counties] & $101[47]$ & $103[47]$ & $92[41]$ & $92[41]$ & $92[41]$ \\
\hline & 0.525 & 0.555 & & & \\
\hline Sargan $\rho$-value & & & 0.140 & 0.071 & 0.271 \\
\hline
\end{tabular}


Figure 1: Federalism pattern around the world, 1960-95.

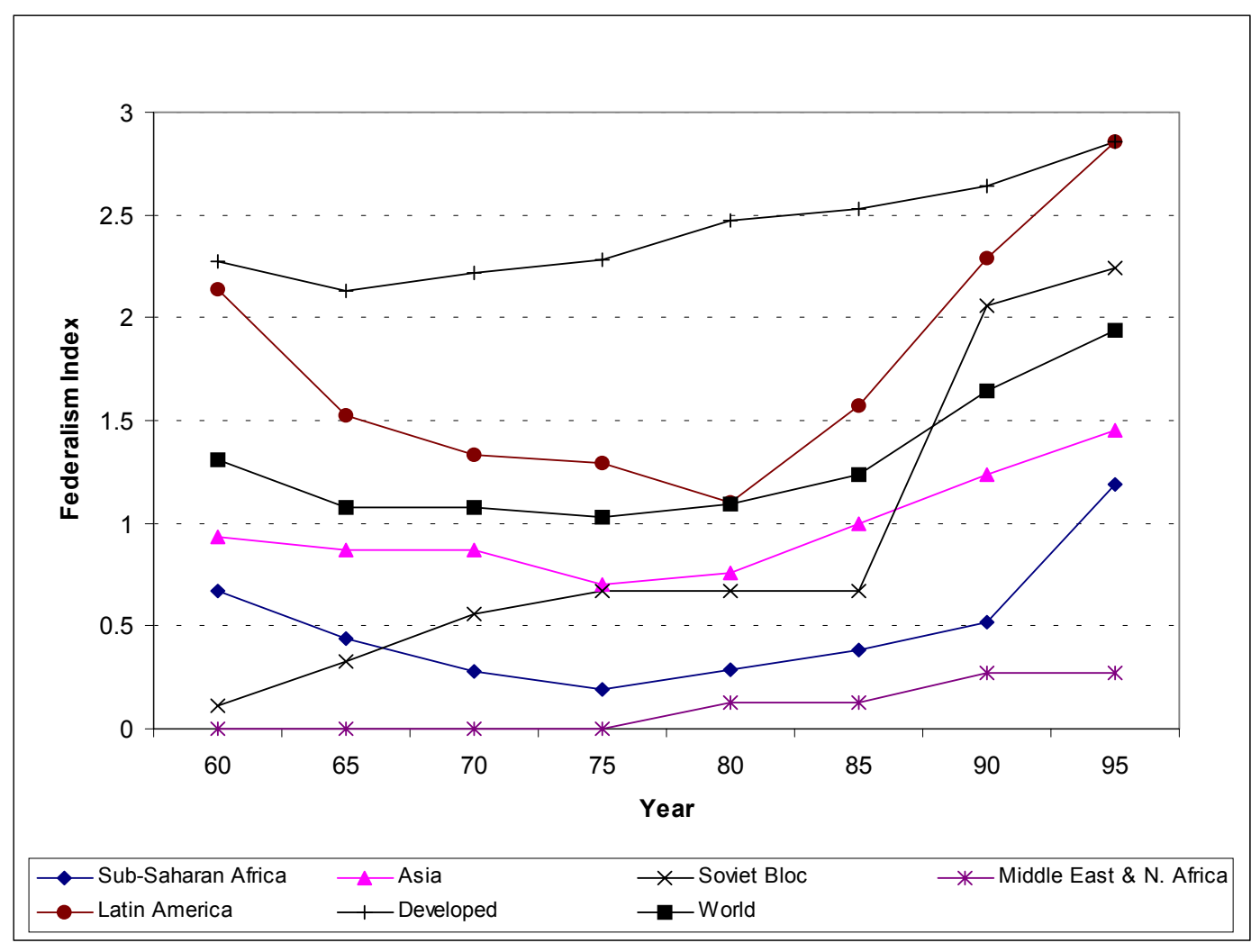


Figure 2: Democracy pattern around the world, 1965-95.

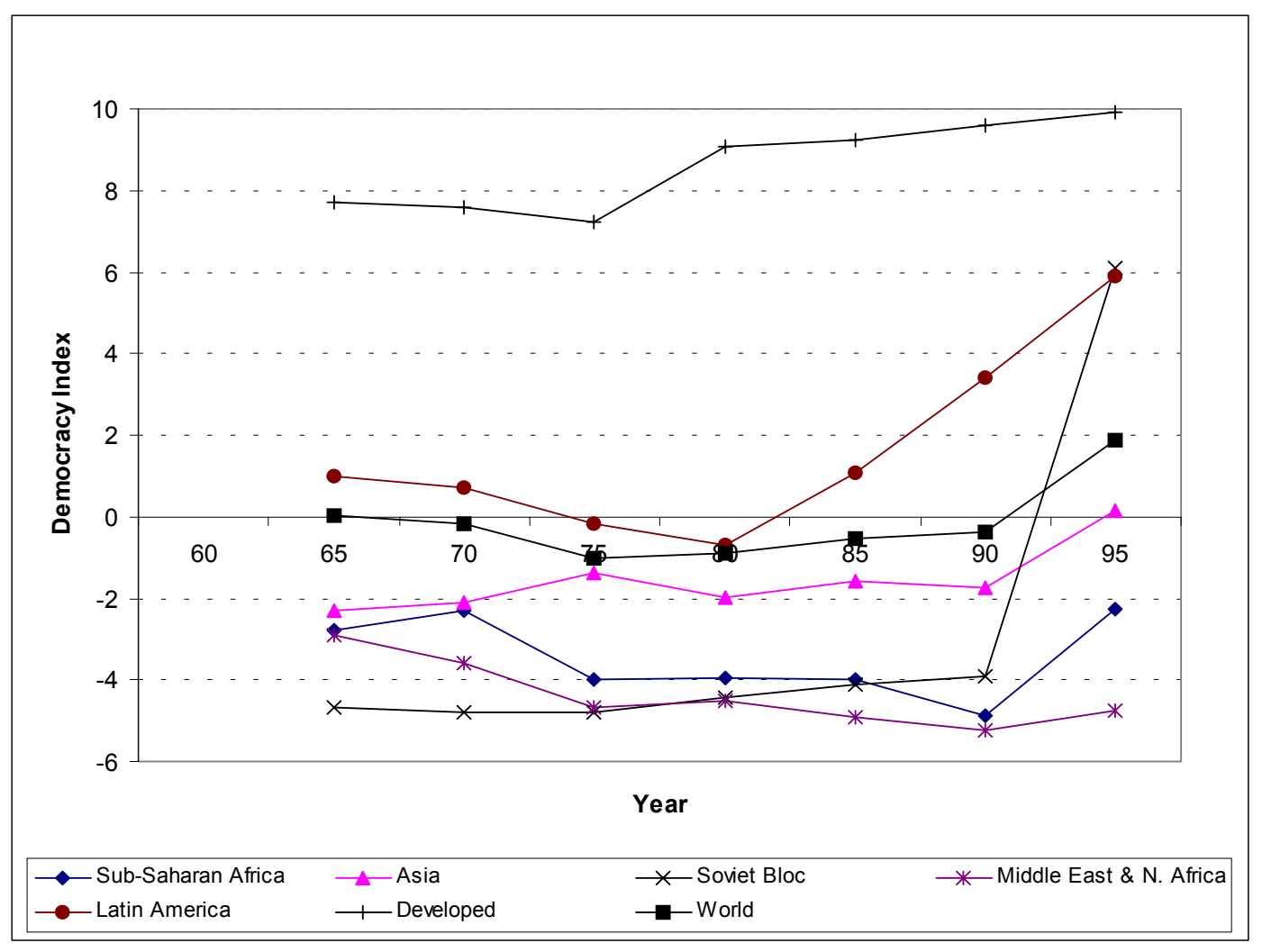


Figure 3: Share of the central government in total government expenditures, 1975-95.

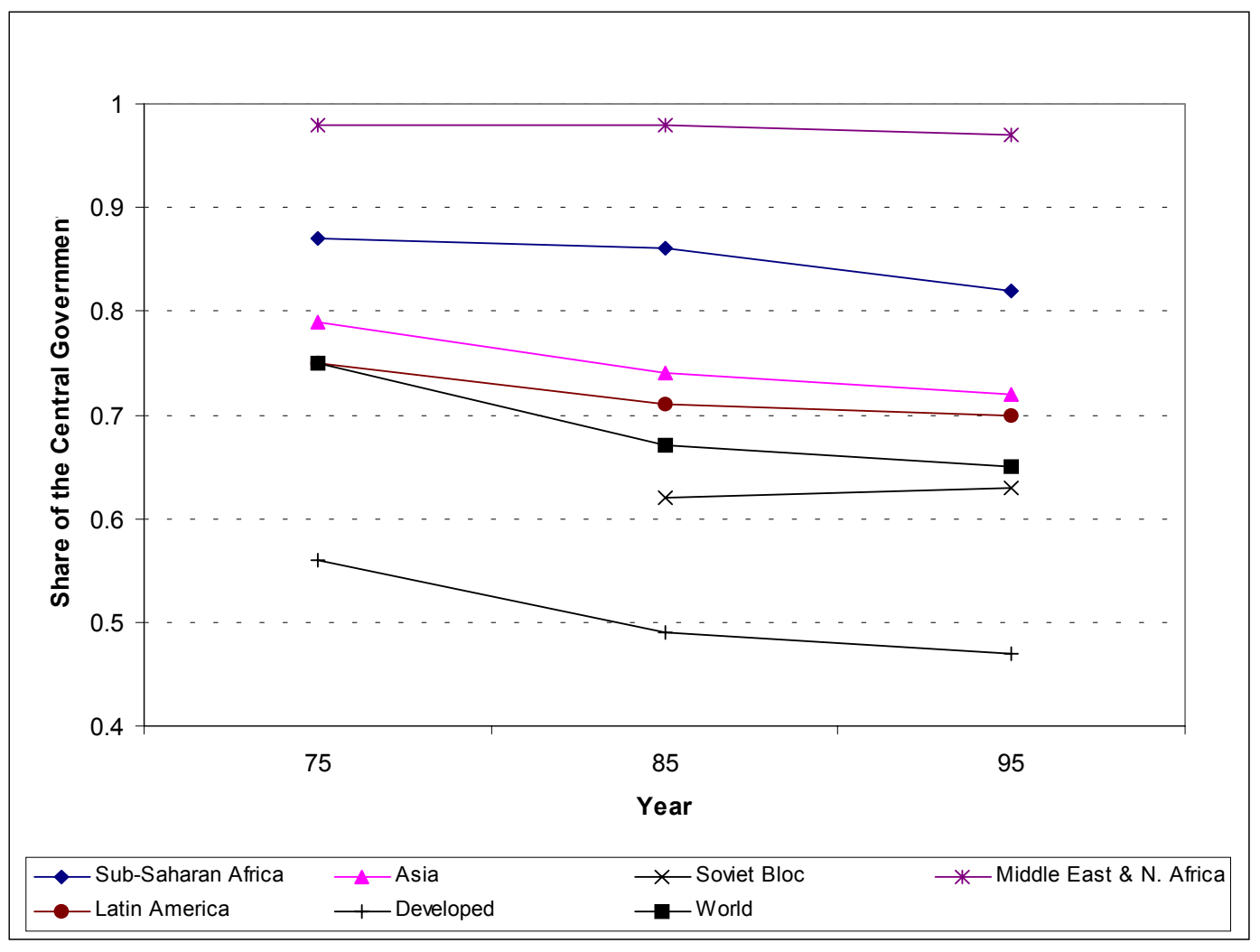

